\title{
Prevalence of Nutrition- Impact Symptoms at Different Disease Stages among Paediatric Cancer Patients Undergoing Chemotherapy at Moi Teaching and Referral Hospital, Eldoret, Kenya
}

\section{Okemwa Julian Nyaboke}

Department of Foods, Nutrition and Dietetics, Kisii University, P.O Box 408-40200, Kisii, Kenya.

\# corresponding author.
Type of Review: Peer Reviewed.
DOl: http://dx.doi.org/10.21013/jas.v15.n3.p2
How to cite this paper:
Nyaboke, O. (2020). Prevalence of Nutrition- Impact Symptoms at Different Disease Stages
among Paediatric Cancer Patients Undergoing Chemotherapy at Moi Teaching and Referral
Hospital, Eldoret, Kenya. IRA International Journal of Applied Sciences (ISSN 2455-4499), 15(3), 48-
54. doi:http://dx.doi.org/10.21013/jas.v15.n3.p2

(C) Institute of Research Advances.

(cc) BY-NC

This work is licensed under a Creative Commons Attribution-Non Commercial 4.0 International License subject to a proper citation to the publication source of the work.

Disclaimer: The scholarly papers as reviewed and published by the Institute of Research Advances (IRA) are the views and opinions of their respective authors and are not the views or opinions of the IRA. The IRA disclaims of any harm or loss caused due to the published content to any party.

Institute of Research Advances is an institutional publisher member of Publishers International Linking Association Inc. (PILA-CrossRef), USA. The institute is an institutional signatory to the Budapest Open Access Initiative, Hungary advocating the open-access of scientific and scholarly knowledge. The Institute is a registered content provider under Open Access Initiative Protocol for Metadata Harvesting (OAI-PMH).

The journal is indexed \& included in CAS Source Index of Chemical Abstracts Service of American Chemical Society (USA), Index Copernicus (IC Value 85.27), WorldCat Discovery Service (USA), CrossRef Metadata Search (USA), WorldCat (USA), OCLC (USA), Open J-Gate (India), EZB (Germany) Scilit (Switzerland), Airiti (China), Bielefeld Academic Search Engine (BASE) of Bielefeld University, Germany, PKP Index of Simon Fraser University, Canada. 


\begin{abstract}
Malnutrition incidence among patients with cancer ranges from 30\% - 80\% globally. Cancer is a major cause of death in Kenya after cardiovascular and infectious diseases. This research assessed the relationship between nutritional status and quality of life $(Q o L)$ of the 52 paediatric cancer patients undergoing chemotherapy at Moi Teaching and Referral Hospital (MTRH) Eldoret, Kenya. A cross-sectional analytical design was applied and the researcher administered a questionnaire and Nutritional Risk Screening (NRS-2002) instruments were used for data collection. The statistical package for social sciences (SPSS) version 21 was used to analyse the data descriptively. The findings revealed that nutrition impact symptoms were more pronounced in the second and third stages of cancer where most of the respondents experienced vomiting (94.3\%), decreased appetite (80.8\%), and diarrhoea (69.23\%). The use of the Nutrition Impact Symptom (NIS) checklist in the paediatric oncology clinic/ward triggers more therapeutic interventions. The awareness for NIS will likely evoke more research in assessment, impact, and treatment.
\end{abstract}

Key Words: Cancer, Paediatric, Nutritional status

\title{
Introduction
}

Childhood cancer is a major public health problem in many parts of the world. Globally it is estimated that cancer kills over 7.9 million people every year with $13 \%$ of total deaths worldwide and 14 million new cases annually (Stewart, 2014). Childhood cancer is a leading cause of child mortality in developed countries as well as a recognized contributor to malnutrition and death in developing countries, in particular those of low socioeconomic status (Chukwu, Ezenwosu, Ukoha, Ikefuna \& Emodi, 2016).

In Kenya, cancer ranks among the top causes of death with 7\% national mortality every year after infectious diseases and cardiovascular diseases. The medical treatment of most cancer children is usually more emphasized than the nutritional management although the two need to complement each other (Bauer, Jürgens \& Frühwald, 2011). Malnutrition is much more common in low and middle-income countries where the prevalence in children with cancer has been reported to be almost as high as 90\% (Barr, Antillon, Agarwal, Mehta \& Ribeiro, 2011). Adequate nutrition during cancer plays an important role in clinical outcome measures, such as treatment response, quality of life and cost of care (Khalil, El-Sharkawy, Gomaa \& Zaghamir, 2013).

Children experience many side effects related with chemotherapy during cancer treatment (Woodgate, 2008; Arslan, Basbakkal, \& Kantar, 2013; Rodgersa et al., 2013). Nutritional challenges during active therapy for cancer are; decreased appetite, early satiety and fatigue, swallowing difficulties, dry mouth, mouth sores, odor sensitivities, taste changes, diarrhea, constipation, nausea, and vomiting (Kubrak et al., 2009, Malihi et al., 2009; Patlan, 2009; Krull et al., 2013; Pound et al., 2012; Rodgersa et al., 2013). Symptoms can occur immediately or much later after chemotherapy administration and can last from several hours to days. (Malihi et al., 2013; Patlan, 2009; Krull et al., 2013)

Anorexia, the loss of appetite or desire to eat, is typically present in $15 \%$ to $25 \%$ of all cancer patients at diagnosis and may also occur as a side effect of treatments (Dy, Lorenz, Naeim, Sanati, Walling \& Asch, 2008). Anorexia can hasten the course of cachexia which is estimated to be the immediate cause of death in $20 \%$ to $40 \%$ of cancer patients; it can develop in individuals who appear to be eating adequate calories and protein but have primary cachexia whereby tumor-related factors prevent maintenance of fat and muscle (Bauer et al., 2011). Thus, the most prudent and advantageous approach to cachexia is the prevention of its initiation through nutrition monitoring and nutrition intervention (Mantovani et al., 2008).

Nausea is a troublesome and distressing symptom for patients receiving chemotherapy. While vomiting may be well controlled with current antiemetics, nausea is a more difficult symptom to manage (Philips et al., 2010, Aseeri Mukhtar, Al Khansa, Elimam, \& Jastaniah, 2013; Farrell, Brearley, Pilling, \& Molassiotis, 2013). Depression, loss of personal interests or hope, and anxious thoughts may be enough to bring about anorexia and result in Protein Calorie Malnutrition (Dy et al., 2008). Despite the impact they cause on oral nutritional intake, they have rarely been systematically assessed (Omlin et al., 2013)

Adequate nutrition during cancer plays a decisive role in several clinical outcome measures, such as treatment response, quality of life, and cost of care. However, the importance of nutrition in children and young adults with malignancies is still an underestimated topic within pediatric oncology (Barr, 2010). Children with cancer are particularly vulnerable to malnutrition because they exhibit elevated substrate needs due to the disease and 
its treatment. At the same time, children have increased requirements of nutrients to attain appropriate growth and neurodevelopment (Bauer et al., 2011).

Malnutrition has been associated with an increased risk of prolonged length of hospital stay and decreased quality of life in cancer patients (Nourissat et al., 2008). Malnutrition globally impacts all cancer patient by increasing the risk of infection, delaying wound healing, increasing treatment toxicity, prolonging hospital stay and increasing health related costs. While it is already a proven fact that malnutrition is prevalent among cancer patients, its impact on the quality of life of patients has not been adequately studied (Vergara, Montoya, Luna, Amparo \& Cristal-Luna, 2013)

Nutritional support is of great importance in managing children with cancer. It may help to reverse malnutrition seen at diagnosis, prevent malnutrition associated with the cancer treatment and promote weight gain and growth. Nutritional support may be provided through parenteral nutrition or enteral nutrition (Shikuri, 2005). People with cancer have low levels of glutamine. Supplemental glutamine is often given to malnourished cancer patients undergoing chemotherapy or radiation treatments and sometimes used in patients undergoing bone marrow transplants. Glutamine seems to help reduce stomatitis caused by chemotherapy. Some studies, have suggested that taking glutamine orally may help reduce diarrhoea associated with chemotherapy (Connie et al., 2005).

\section{Objective of the Study}

The main objective of the study was to determine the prevalence of nutrition-impact symptoms at different disease stages after the commencement of chemotherapy of children with cancer aged (1-17) years in MTRH, Eldoret.

\section{Methodology}

\section{Research design}

The study adopted a cross-sectional analytical method (Gravetter \& Forzano, 2011)

to assess the nutritional status and quality of life of paediatric cancer patients who were undergoing chemotherapy at Moi Teaching and Referral Hospital.

\section{Study population}

The study targeted children aged between (1-17) years on chemotherapy who attended the Hemato-oncology clinic in MTRH Uasin Gishu County.

\section{Sample size determination}

Using the fisher formula and the finite population correction factor a sample size of 52 was used in the study.

\section{Sampling Techniques}

Purposive sampling was used given that there was a small population of approximately 20 patients per month on chemotherapy. The study used all the eligible participants until the required sample size of 52 was obtained.

\section{Research Instruments}

A researcher administered questionnaire was used to collect data on nutrition impact symptoms. A medical history form was used to collect data on the type and stage of cancer and any other health complication that the respondent was having. Nutritional risk form (NRS-2002) was used to collect data on the stress factor, ability to eat/retain food, appetite and the weight of the respondent.

\section{Pre-Testing of instruments}

The questionnaires were pre-tested to check on the length, content, question wording and language. The questionnaire was administered to five respondents in the paediatric oncology unit in Kenyatta National Hospital.

\section{Data analysis and presentation.}

Completed questionnaires were checked on a daily basis for accuracy and completeness in recoding of responses. Editing and coding was done before data entry. Data was entered and analyzed using SPSS version 21 and presented in the form of descriptive statistics such as frequencies and percentages. 


\section{Findings and Discussion}

\section{Cancer stage of respondents}

Figure 1 shows cancer stages of the respondents. $46 \%$ were in cancer stage three, $38 \%$ were in cancer stage two, $10 \%$ in stage four and $6 \%$ in stage one.

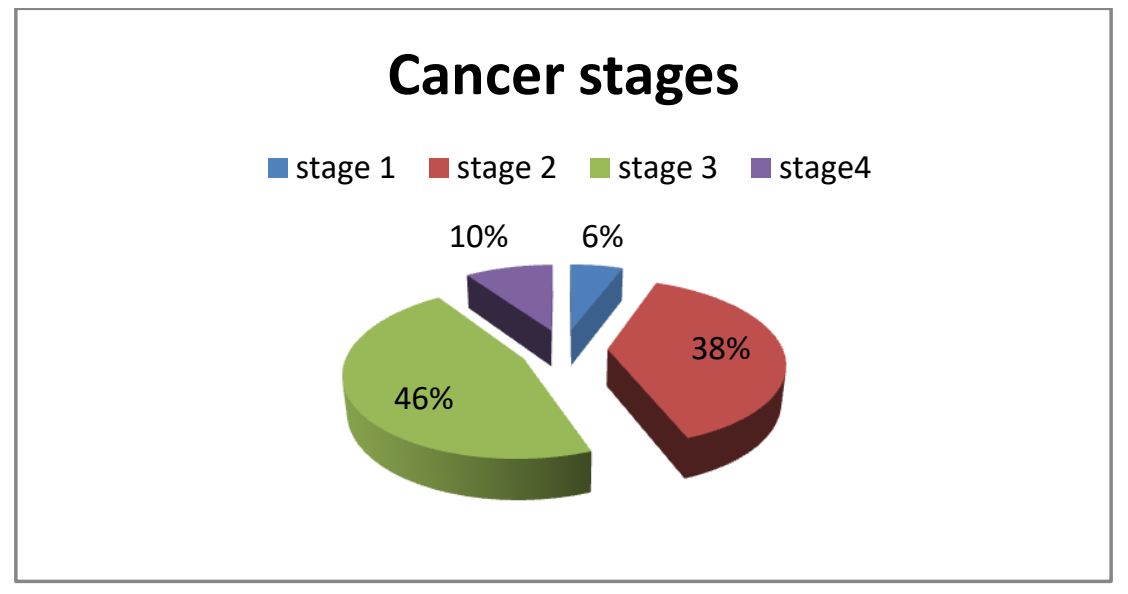

Figure 1: Cancer stages of the respondents

\subsection{2: Nutritional Impact Symptoms of the respondents}

Among the 52 respondents more than three quarters experienced decreased appetite $(n=42)$ and vomiting $(n=49)$. Two-thirds experienced diarrhoea $(n=36)$ while less than two-thirds had nausea $(n=30)$. Few of them $(\mathrm{n}=23)$ experienced taste changes as shown in figure 2 .

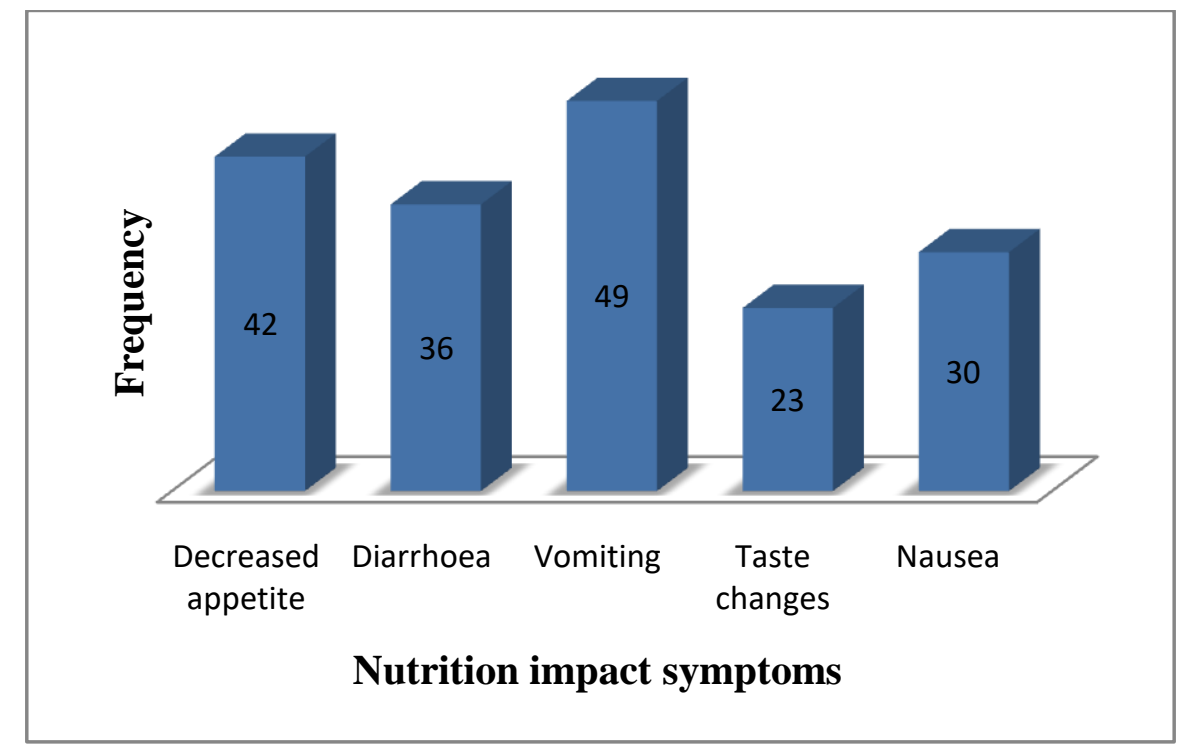

Figure 2: Nutrition impact symptoms of the respondents

\section{Prevalence of Nutritional Impact Symptoms at different cancer stages of the respondents}

Nutrition impact symptoms were more pronounced in the second and third stages of cancer. Most of the respondents experienced diarrhoea $(n=36,69.2 \%)$, decreased appetite $(n=42,80.8 \%)$ and vomiting $(n=49,94.3 \%)$. Majority of them were in the third stage of cancer $(n=17,47.2 \%),(n=20,47.6 \%)$ and $(n=21,42.9 \%)$ respectively. Among the respondents who experienced taste changes $(n=23,44.2 \%)$, more than half of the respondents were in stage three $(n=14,60.9 \%)$. For those respondents who experienced nausea $(n=30,57.7 \%)$ slightly more than half $(n=16,53.3 \%)$ were in the third stage of cancer. Decreased appetite $(n=17,40.8 \%)$ had no significant difference when compared to vomiting $(n=20,40.8 \%)$ in stage two. On the same stage, twelve respondents experienced 
diarrhoea $(33.3 \%)$. The prevalence of the nutrition impact symptoms generally increased from stage one to stage three but dropped in the final stage as shown in figure 3.

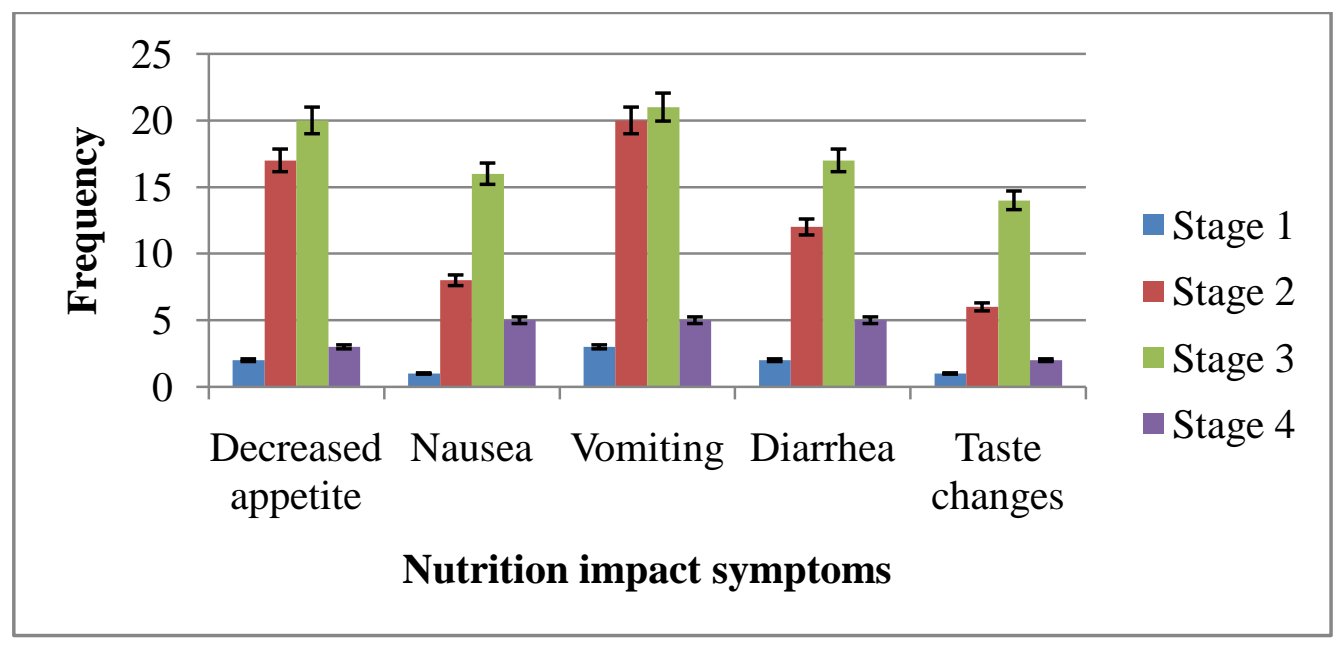

Figure 3: Nutrition impact symptoms at different cancer stages

The findings reveal that the nutrition impact symptoms were more pronounced in respondents with advanced tumor stage II and III. This is because as treatment becomes more vigorous and as the disease advances the patients tend to develop more nutritional problems since their food intake is affected. This results contrast with those of a study by Omlin et al., (2013), who reported that nutrition impact symptom load in patients with advanced tumor stage III or IV is high and reported that taste alterations reach up to $50 \%$ which was higher than the findings of the current study $(n=23,44.23 \%)$. The possible reason for the contrast could be because most of the respondents happened to be in cancer stage $2(38 \%)$ and three $(46 \%)$.

Though vomiting nowadays is well controlled with antiemetics, it occurs in many of the patients (Philips et al., 2010; Aseeri et al., 2013; Farrel et al., 2013). In the present study, almost all of the respondents $(\mathrm{n}=49,94.2 \%)$ experienced vomiting. These figures are to those reported by Pietsch et al., (2000), who reported that vomiting occurred in the majority of the respondents $(71 \%)$, which was associated with chemotherapy.

Anorexia, the loss of appetite or desire to eat, is typically present in $15 \%$ to $25 \%$ of all cancer patients at diagnosis and may also occur as a side effect of treatments (Dy et al., 2008; Omlin et al., 2013). In this study, $80.8 \%$ of the respondents $(n=42)$ experienced poor appetite. Poor appetite was more prevalent in those respondents in stage II $(n=17,40.8 \%)$ and III $(n=20,47.6 \%)$. Anorexia can hasten the course of cachexia which is estimated to be the immediate cause of death in $20 \%$ to $40 \%$ of cancer patients; it can develop in individuals who appear to be eating adequate calories and protein but have primary cachexia whereby tumor-related factors prevent maintenance of fat and muscle (Bauer et al., 2011). Thus, the most prudent and advantageous approach to cachexia is the prevention of its initiation through nutrition monitoring and nutrition intervention (Mantovani et al., 2008).

Cases of nausea were very serious in most patients. In this study $57.7 \%(n=30)$ of the respondents experienced nausea. As acknowledged by many authors nausea is a troublesome and distressing symptom for patients receiving chemotherapy. Whereas vomiting can be well controlled with most antiemetics, nausea is a more difficult symptom to manage (Philips et al., 2010; Aseeri et al., 2013; Farrel et al., 2013). Many authors (Burges et al., 2010; Omlin et al., 2013) agree that early identification of chemotherapy-related side effects and their appropriate management may help to reduce their impact on the patient's nutritional status A study by Del et al., (2011) confirmed that the frequent occurrence of two to three nutrition impact symptoms per patient had an association with weight loss. 


\section{Conclusion}

Nutrition impact symptoms were more pronounced in respondents with advanced tumor stage II and III. This is because as treatment becomes more vigorous and as the disease advances the patients tend to develop more nutritional problems since their food intake is affected and also most of the respondents were in cancer stage two and three. Vomiting, decreased appetite and diarrhoea were the more prevalent NIS among the cancer children.

\section{Recommendations}

This research should be carried out in other hospitals with systematic sampling procedures. There is need to investigate the effect of chemotherapy on poor appetite because in the recent study three quarters $(\mathrm{N}=42$, $80.77 \%$ ) of the respondents experienced it. Intervention studies are also needed to evaluate the impact of interventional management of nutrition impact symptoms on improving nutritional intake. Further research should be conducted to assess nurses knowledge about chemotherapy side effects and its management, prevention and management of pediatric nutritional disorders. It is worth recommending that social, physiological together with spiritual well-being of children with cancer be evaluated and appropriate care initiatives be implemented to improve their quality of life.

\section{Acknowledgment}

I take this opportunity to thank the staff of the cancer clinic at Moi Teaching and Referral Hospital (MTRH), Eldoret, Kenya for their cooperation and useful role played towards the collection of the required data for this research work.

\section{References}

[1]. Arslan, F.T., Basbakkal, Z. \&Kantar, M. (2013). Quality of Life and Chemotherapy-related Symptoms of Turkish Cancer Children Undergoing Chemotherapy. Asian Pacific Journal of Cancer Prevention, 14(3), 1761-1768.

[2]. Aseeri M., Mukhtar, A., Al Khansa, S., Elimam, N. \& Jastaniah, W.(2013). A retrospective review of antiemetic use for chemotherapy-induced nausea and vomiting in pediatric oncology patients at a tertiary care center. Journal of Oncology Pharmacy Practice, 19(2), 138-144.doi: 10.1177/1078155212457966.

[3]. Barr, R., Antillon, F., Agarwal., Mehta, P., \& Ribeiro, R.(2011). Pediatric oncology in countries with limited resources. In: Pizzo PA, Poplack DG, editors. Principles and Practice of Pediatric Oncology. 6th ed. Philadelphia: Lippincott Williams and Wilkins. p. 1463-73.

[4]. Barr, R.D. (2010). Assessing the impact of nutritional status on clinical outcomes in children and adolescents with cancer: A focus on the contributions from Mexico. Revista de Hematología, 11(1), 25-29.

[5]. Bauer, J., Jürgens, H \& Frühwald, M.C. (2011). Important aspects of nutrition in children with cancer. Advances in Nutrition2,67-77.doi:10.3945/an.110.000141

[6]. Borges, L.R., Paiva, S.I., Silveira, D.H., Assunção, M.C.F. \& Gonzalez, M.C. (2010). Can nutritional status influence the quality of life of cancer patients? Review NutritionCampinas, 23(5), 745-753.doi: 10.1590/s141552732010000500005

[7]. Chukwu, B.F., Ezenwosu, O.U., Ukoha, O.M., Ikefuna, A.N. \&Emodi, I.J. (2016) Nutritional Status of Children with Cancer at the University of Nigeria Teaching Hospital, Ituku/Ozalla, Enugu, Nigeria. Journal of Cancer Prevention \& Current Research, 5(4), 00167. doi:10.15406/jcpcr.2016.05.00167

[8]. Del, F. E., Hui, D., Dalal, S., Dev, R., Nooruddin, Z.I.\&Bruera, E. (2011). Clinical outcomes and contributors to weight loss in a cancer cachexia clinic. Journal of Palliative Medicine. 14(9):1004-1008. doi:10.1089/jpm.2011.0098.

[9]. Dy, S.M., Lorenz, K.A., Naeim, A., Sanati, H., Walling, A. \&Asch, S.M. (2008). Evidence-based recommendations for cancer fatigue, anorexia, depression, and dyspnea. Journal of clinical oncology: official journal of the American Society of Clinical Oncology.26(23), 3886-3895. doi:10.1200/JCO.2007.15.9525.

[10].Farrell, C., Brearley, S.G., Pilling, M. \& Molassiotis, A. (2013). The impact of chemotherapy-related nausea on patients' nutritional status, psychological distress and quality of life. Supportive care in cancer: official journal of the Multinational Association of Supportive Care in Cancer,21(1), 59-66. doi:10.1007/s00520-012-1493-9

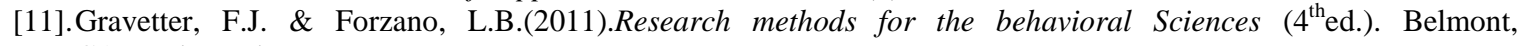
CA:Wadsworth.

[12].Khalil, A.A., El-Sharkawy, S.G., Gomaa, K.A.E. \&Zaghamir, D.E. (2013). Evaluation of nutritional status of children suffering from cancer under chemo-radiotherapy. Medical Journal of Cairo University, 81(2), 163-171.

[13].Krull, K.R., Hockenberry, M.J., Miketova, P., Carey, M\&Moore, I.M. (2013). Chemotherapy-related changes in central nervous system phospholipids and neurocognitive function in childhood acute lymphoblastic leukemia. Leukemia \& lymphoma, 54(3), 535-540. doi:10.3109/10428194.2012.717080

[14].Malihi, Z., Kandiah, M., Chan, Y.M., Hosseinzadeh, M., Sohanaki, A.M. \&Zarif Y.M. (2013). Nutritional status and quality of life in patients with acute leukaemia prior to and after induction chemotherapy in three hospitals in 
Tehran, Iran: a prospective study. Journal of human nutrition and dietetics: the official journal of the British Dietetic Association26(1), 123-131. doi:10.1111/jhn.12043.

[15].Mantovani, G., Macciò, A., Madeddu, C., Gramignano, G., Serpe, R., Massa, E., ... Floris, C. (2008). Randomized phase III clinical trial of five different arms of treatment for patients with cancer cachexia: interim results. Nutrition (Burbank, Los Angeles County, Calif.),24(4), 305-313. doi:10.1016/j.nut.2007.12.010

[16].Nourissat, A., Vasson, M.P, Merrouche, Y., Bouteloup, C., Goutte, M. \& Mille, D., Chauvin F. (2008). Relationship between nutritional status and quality of life in patients with cancer. European Journal of Cancer (Oxford, England: 1990),44(9), 1238-1242. doi: 10.1016/j.ejca.2008.04.006.

[17].Omlin, A., Blum, D., Wierecky, J., Haile, S.R., Ottery, F.D,\&Strasser, F.(2013). Nutrition impact symptoms in advanced cancer patients: frequency and specific interventions, a case-control study. Journal of Cachexia, Sarcopenia and Muscle,4(1),55-61. doi: 10.1007/s13539-012-0099-x

[18].Patlan, J.T. (2009). Nausea. In Yeung, S. J., Escalante, C. P., \&Gagel, R. F.(Eds), Medical Care of Cancer Patients $\left(1^{\text {st }}\right.$ ed., pp. 92-100). USA: People's Medical Publishing House.

[19].Phillips, R. S., Friend, A.J., Gibson, F., Houghton, E., Gopaul, S., Craig, J. V.\&Pizer, B. (2010).Antiemetic medication for prevention and treatment of chemotherapy-induced nausea and vomiting in childhood. University of York, UK. The cochrane database of systematic review.2. doi:10.1002/14651858.CD007786.

[20].Pietsch, J. B., \& Ford, C. (2000). Children with Cancer: Measurements of Nutritional Status at Diagnosis. Nutrition in Clinical Practice, 15(4), 185-188. doi:10.1177/088453360001500406

[21].Rodgersa, C. C., Hookeb, M. C. \& Hockenberry, M.J. (2013). Symptom clusters in children. Current Opinion in Supportive \& Palliative Care, 7, 67-72

[22].Shikuri, R.M. (2005). Nutritional Status and Food Consumption patterns of children with cancer: A case of Kenyatta National Hospital, Kenya. MSc Thesis

[23].Stewart, B.W. \& Wild, C.P.(Eds.). (2014). World cancer report. WHO.

[24].Vergara, N., Montoya, J., Luna, H., Amparo, R. \& Cristal-Luna, G. (2013). Quality of Life and Nutritional Status Among Cancer Patients on Chemotherapy. DOI 10. 5001/omj.2013.75 Oman Medical Journal (2013) Vol. 28, No. 4:270-274

[25].Woodgate, R. L (2008). Feeling states: a new approach to understanding how children and adolescents with cancer experience symptoms. Cancer Nursing, 31, 229-38. 